OPEN ACCESS

Edited by:

Rebecca Dunlop,

The University of Queensland,

Australia

Reviewed by:

Stephen J. Trumble,

Baylor University, United States

Greta Dalle Luche,

Provectus Algae Pty Ltd., Australia

*Correspondence:

Céline A. J. Godard-Codding

celine.godard@ttu.edu

Specialty section: This article was submitted to

Marine Megafauna,

a section of the journal

Frontiers in Marine Science

Received: 03 November 2021

Accepted: 22 December 2021

Published: 13 January 2022

Citation:

Wittmaack C, Urbán Ramírez J, Bernot-Simon D, Martínez-Aguilar S,

Subbiah S, Surles JG, Looney M,

Kumar N, Halaska B, Duignan PJ,

Knauss M, Burns $K$ and

Godard-Codding CAJ (2022) Small Blubber Samples (50 mg) Sufficient

for Analyses of 10 Stress

and Reproductive Steroid Hormones

in Gray and Fin Whales via Liquid

Chromatography Mass Spectrometry.

Front. Mar. Sci. 8:808764.

doi: 10.3389/fmars.2021.808764

\section{Small Blubber Samples (50 mg) Sufficient for Analyses of 10 Stress and Reproductive Steroid Hormones in Gray and Fin Whales via Liquid Chromatography Mass Spectrometry}

\author{
Christiana Wittmaack ${ }^{1}$, Jorge Urbán Ramírez ${ }^{2}$, Daniela Bernot-Simon ${ }^{2}$, \\ Sergio Martínez-Aguilar ${ }^{2}$, Seenivasan Subbiah', James G. Surles ${ }^{3}$, Mary Looney ${ }^{1}$, \\ Naveen Kumar', Barbie Halaska4, Pádraig J. Duignan', Madelyn Knauss', \\ Kristen Burns ${ }^{1}$ and Céline A. J. Godard-Codding ${ }^{1 *}$
}

\footnotetext{
${ }^{1}$ The Institute of Environmental and Human Health, Texas Tech University, Lubbock, TX, United States, ${ }^{2}$ Departamento de Ciuencias Marinas y Costeras, Universidad Autónoma de Baja California Sur, La Paz, Mexico, ${ }^{3}$ Department of Mathematics and Statistics, Texas Tech University, Lubbock, TX. United States, ${ }^{4}$ The Marine Mammal Center, Sausalito, CA, United States
}

Information on stress, reproductive fitness, and health is difficult to obtain in wild cetaceans but critical for conservation and management. The goal of this study was to develop a methodology requiring minimal blubber mass for analysis of reproductive and stress steroid hormones and, hence, suitable for cetacean biopsies. Blubber biopsies and samples were collected from free-ranging and stranded gray and fin whales. Steroid hormones were extracted from blubber samples as small as $50 \mathrm{mg}$ using liquidliquid extraction methodology developed to handle the high fat content of blubber. Samples were analyzed via liquid chromatography with tandem mass spectrometry for 10 hormones: aldosterone, androstenedione, cortisol, cortisone, corticosterone, $17 \beta$-estradiol, estrone, $17 \alpha$-hydroxyprogesterone, progesterone, and testosterone. As part of the optimization, homogenization via bead beating and blade dispersion were compared, and the former found superior. To investigate optimal yet minimal tissue mass required, hormone panels were compared among paired 50, 150, and $400 \mathrm{mg}$ samples, the latter two being commonly reported masses for hormone blubber analysis. Results indicated that $50 \mathrm{mg}$ of blubber was suitable and sometimes superior. Additionally, significant differences in precision values were observed between species, possibly stemming from differences in blubber composition, and relevant to homogenization technique selection and calibration methods that use blubber matrix matches obtained from a species other than the study species. Based on recovery and precision values, our methodology was accurate and precise in the measurement of spiked known quantities for all 10 hormones, confirming the methodology capabilities in 50 mg blubber mass in both species. Altogether, and in our specific sample sets, all endogenous hormones, except corticosterone, were identified above the detection limit in 50 mg gray whale blubber samples while all endogenous hormones, except aldosterone, cortisone, 
estrone, and progesterone, were detected in $50 \mathrm{mg}$ fin whale blubber samples. We present a robust methodology for the analysis of multiple reproductive and stress steroid hormones in minimal masses of cetacean blubber compatible with small biopsies. Finally, we identified statistically significant differences in corticosteroid concentrations between stranded and free ranging animals.

Keywords: steroid hormone, LC-MS/MS, blubber, biopsy, gray whale, fin whale, stress, cetacean

\section{INTRODUCTION}

Information on stress, reproductive fitness, and health can be difficult to obtain in wild cetaceans but is critical for conservation and management (Fair and Becker, 2000; Parsons et al., 2015). Hormone analyses can provide fundamental information on wildlife health and fitness at both individual and population levels (Keay et al., 2006; Kershaw and Hall, 2016; Mello and Oliveira, 2016; McCormick and Romero, 2017). In cetaceans, steroid hormones have been analyzed in wild and captive animals to assess pregnancy, reproductive status, stress, and fitness in a variety of matrices, including baleen, blow, ear plug, feces, follicular fluid, milk, muscle, ocular secretions, plasma, saliva, serum, skin including blubber, and urine (Walker et al., 1988; Yoshioka et al., 1994; Iga et al., 1996; Atkinson et al., 1999; West et al., 2000; Kellar et al., 2006, 2009; Fair et al., 2014; Hunt et al., 2014; Thompson et al., 2014; Champagne et al., 2017; Trumble et al., 2018; Boggs et al., 2019; Carone et al., 2019; Bechshoft et al., 2020; Cates et al., 2020; Galligan et al., 2020; Lemos et al., 2020b; Graham et al., 2021; Melica et al., 2021).

Blubber steroid hormone analysis in large whales has primarily been conducted in individuals that were stranded, by-caught, or killed by ship strikes or native hunts (Mansour et al., 2002; Kellar et al., 2006, 2013, 2015; Trego et al., 2013; Trana et al., 2016; Dalle Luche et al., 2019). Hormone data from these individuals are valuable but characterized by random availability, potentially compromised health status, and possibly skewed glucocorticosteroid levels due to stress experienced during stranding, capture, or death (Atkinson et al., 2015; Kellar et al., 2015; Trana et al., 2016). More recently, hormone values along with demographic trends have been collected from biopsy blubber samples from free-ranging whales (Teerlink et al., 2018; Cates et al., 2019; Goertz et al., 2019; Mingramm et al., 2019). Data on free-ranging animals is essential for management and long-term monitoring of population health.

Two categories of analytical methodologies are used for steroid hormone analysis in cetacean blubber: immunoassaybased and physical separation-based. The latter is more recent and includes analyses combining chromatography and spectrometry such as gas chromatography mass spectrometry and liquid chromatography mass spectrometry (LC-MS). Immunoassays provide sensitivity in the ppt range but are limited by the frequent requirement for 70-150 mg wet weight

Abbreviations: LC-MS, Liquid chromatography mass spectrometry; LC-MS/MS, Liquid chromatography with tandem mass spectrometry; LOD, Limit of detection; LOQ, Limit of quantification; RSD, Relative standard deviation or precision; UME, Unusual mortality event; ww, Wet weight. (ww) of blubber per hormone and the potential for crossreactivity of kit antibodies with steroid hormones of similar structure (Boots et al., 1998; Rotmensch and Cole, 2000; Fanelli et al., 2011; Whitehead et al., 2013; Graham et al., 2021). This relatively large mass requirement can make analyzing multiple hormones challenging, especially when tissue is obtained by biopsy and/or must be split for multiple studies (Godard et al., 2004; Godard-Codding et al., 2011). LC-MS circumvents some of these limitations as multiple hormones can be analyzed concurrently and with high specificity, eliminating cross reactivity issues even among metabolites, and is thus preferred in medicine where the avoidance of false positives is critical (Chace, 2001; Shackleton, 2010). A multi-hormone panel also provides a more accurate assessment of the hormonal crosstalk inherent to most physiological processes (Soldin et al., 2005; Kushnir et al., 2011). However, LC-MS instrumentation is costly, requires extensive training, and while some instruments offer similar sensitivity compared to immuno-based assays, others do not.

We previously developed a liquid chromatography tandem mass spectrometry (LC-MS/MS) with nano-electrospray ionization methodology where cortisol, progesterone, and testosterone were analyzed concurrently using $50 \mathrm{mg}$ ww gray whale (Eschrichtius robustus) blubber (Hayden et al., 2017). Recent studies describe larger hormone panel analyses via LC-MS/MS using blubber sample masses between 100 and 800 mg ww (Boggs et al., 2017, 2019; Dalle Luche et al., 2019, 2021; Galligan et al., 2019, 2020). Here, we report an optimized methodology for the extraction and LC-MS/MS quantification of up to 10 steroid hormones in $50 \mathrm{mg}$ ww blubber of gray and fin whales (Balaenoptera physalus). Our first objective was to minimize the current blubber mass required for multiple hormone analysis. Our second objective was to determine the optimal homogenization technique for precision and recovery. Our third objective was to determine whether the methodology was sensitive enough to detect a range of hormones in both free ranging and stranded whales.

\section{MATERIALS AND METHODS}

\section{Tissue Collection and Permits}

Blubber biopsies were collected in 2018 from seven gray whales (including mothers and calves) in San Ignacio Lagoon, Baja California Sur, Mexico and in 2017-2019 from six fin whales in the Gulf of California, as approved by the Ethics Committee of the Subsecretaría de Gestión Para La Protectión Ambiental of the Mexican Dirección General de Vida Silvestre 
and under the Mexican Ministry of the Environment permit SGPA/DGVS/00612/18. Gray whale sex was unknown for all but one male calf (sexed genetically) and one mother (visually seen accompanied by a calf). Five fin whales were sexed genetically as male, and one was undetermined. Biopsies were shipped frozen to the United States under the Convention on International Trade in Endangered Species of Wild Fauna and Flora permits MX93867 and 17US082589/9. Blubber samples were collected from stranded animals (11 gray and three fin whales) of known sex by the Marine Mammal Center from 1998 to 2019 off the coast of California under MMPA/ESA Permit No. 932- 1905/MA009526. All samples were stored in liquid nitrogen or at $-80^{\circ} \mathrm{C}$ until analysis under the Marine Mammal Health and Stranding Response Program Permit 18786-02. Body condition and life history parameters are reported in Table $\mathbf{1}$ for all whales.

\section{Chemicals/Reagents}

LC-MS grade chemicals including acetonitrile, water, formic acid, ammonium acetate, methanol, and high-performance liquid chromatography grade hexane were purchased from Fisher Scientific (Waltham, MA, United States). Isotopically labeled standard reference materials including aldosterone 2,2,4,6,6,17,21,21-D8, androstene-3,17-dione-2,3,4-13C3, cortisol-D4, 17 $\beta$-estradiol-2,3,4-13C3, estrone-2,3,4-13C3, $17 \alpha$-hydroxyprogesterone-2,3,4-13C3, progesterone 2,3,4-13C3, and testosterone 2,3,4-13C3 were purchased from Cerilliant (Round Rock, TX, United States) or Cambridge Isotope Laboratories Inc. (Tewksbury, WA, United States). Aldosterone, androstenedione, cortisol, cortisone, corticosterone, $17 \beta$-estradiol, estrone, $17 \alpha$-hydroxyprogesterone, progesterone, and testosterone non-labeled standards were purchased from Sigma Aldrich (St. Louis, MO, United States).

\section{Tissue Homogenization Optimization Study}

Optimal homogenization methodology was investigated by comparing precision between bead beating and blade dispersion methods $(n=7)$. Blubber samples $(50 \mathrm{mg}$ ww) were homogenized via bead beating in $1,400 \mu \mathrm{L}$ acetonitrile with lysing matrix A (MP Biomedicals Solon, OH, United States), which consisted of a garnet matrix and a quarter inch ceramic bead, for eight periods of $45 \mathrm{~s}$ at $6.5 \mathrm{~m} / \mathrm{s}$ on a FastPrep ${ }^{\circledR} 24$ (MP Biomedicals) and dry ice, then vortexed for $30 \mathrm{~s}$ and centrifuged at 5,000 $\mathrm{g}$ for $5 \mathrm{~min}$. Blade dispersion was achieved with a polytron (PT 3100 D, Kinematica, NY, United States) fitted with a $12 \mathrm{~mm}$ coupling type B probe (PT-DA 12/2EC-B154). Samples were placed in chilled polypropylene tubes with $3 \mathrm{~mL}$ acetonitrile (the minimal volume for the polytron and final volume in the extraction procedure) and homogenized at $1,700 \mathrm{~g}$ for $5 \mathrm{~min}$. This was repeated eight times. Tubes were vortexed and centrifuged at $1,800 \mathrm{~g}$ for $6 \mathrm{~min}$ before extraction.

\section{Liquid-Liquid Steroid Hormone Extraction}

Following the tissue homogenization study, all subsequent samples were homogenized via bead beating. Once the homogenization of $50 \mathrm{mg}$ ww blubber was complete, the supernatant was transferred to a clean tube and the homogenization tube rinsed with $800 \mu \mathrm{L}$ acetonitrile. This was repeated twice. Samples were vortexed and centrifuged prior to the addition of $2.75 \mathrm{~mL}$ hexane (vortexed $30 \mathrm{~s}$ ). Once immiscible layers separated, hexane was removed, and the process repeated thrice. Tubes were incubated at $-20^{\circ} \mathrm{C}$ overnight. Supernatants were evaporated using a TurboVap LV ${ }^{\mathrm{TM}}$ (Biotage, Sweden) and residues reconstituted in $500 \mu \mathrm{L}$ of methanol, vortexed, sonicated, and filtered through $0.22 \mu \mathrm{m}$ cellulose acetate spin filters. Supernatants were evaporated, reconstituted in $50 \mu \mathrm{L}$ isotopically spiked methanol, then stored at $-20^{\circ} \mathrm{C}$ until analysis. Ratio of extraction solvents to tissue mass was kept consistent for 150 and $400 \mathrm{mg}$ ww samples.

\section{Liquid Chromatography and Mass Spectrometry}

Androstenedione, cortisol, cortisone, corticosterone, $17 \alpha$-hydroxyprogesterone, progesterone, and testosterone were analyzed with a Dionex Ultimate 3,000 ultra-high performance liquid chromatography system coupled with a TSQ Endura triple quadrupole mass spectrometer (Thermo Fisher Scientific). Ionization was achieved with a HESI probe and analysis occurred in positive ion mode. Mobile phases were $0.1 \%$ formic acid water and $0.1 \%$ formic acid acetonitrile. The analytes were separated via the following gradient program: $5 \%$ of $0.1 \%$ formic acid acetonitrile was held for $4 \mathrm{~min}$, increased to $95 \%$ over the next $4 \mathrm{~min}$, then held for $4 \mathrm{~min}$ before being returned to initial conditions over a period of $4 \mathrm{~min}$. Aldosterone, $17 \beta$-estradiol, and estrone were analyzed in negative ion mode with a Thermo Scientific Accela 1250 Pump and Autosampler high performance liquid chromatography system coupled with a TSQ Quantum Access Max triple stage quadrupole mass spectrometer. Ionization of $17 \beta$-estradiol and estrone were performed with an atmospheric pressure chemical ionization probe and mobile phases consisted of water and methanol. The separation of analytes was performed with the following gradient program: 40\% LC-MS grade methanol was held for $2.5 \mathrm{~min}$, increased to $83 \%$ over the next $9 \mathrm{~min}$, and then increased to $100 \%$ over $30 \mathrm{~s}$. The 100\% LC-MS grade methanol was held for $2 \mathrm{~min}$ at which time the gradient returned to initial conditions over a period of $10 \mathrm{~s}$. The ionization of aldosterone was performed with a HESI probe and mobile phases consisted of water with $20 \mathrm{mM}$ ammonium acetate and methanol. The separation of analytes was achieved via the following gradient program: 5\% methanol was held for $3 \mathrm{~min}$ and then increased to $95 \%$ methanol over the next $3 \mathrm{~min}$. This was then held for $3 \mathrm{~min}$ before increasing to $100 \%$ over the next $2 \mathrm{~min}$. Finally, the gradient was returned to initial conditions over a period of $1 \mathrm{~min}$. All hormone separations were performed on a C18 column (Kinetex ${ }^{\circledR}, 2.6 \mu \mathrm{m}$ C18 $100 \AA$ LC Column $50 \times 2.1 \mathrm{~mm}$ ) maintained at $30^{\circ} \mathrm{C}$ with a $300 \mu \mathrm{L} / \mathrm{min}$ flow rate. Injection volume was $5 \mu \mathrm{L}$, except for three fin whales $(10 \mu \mathrm{L})$. Additionally, these three animals were analyzed for estrogens with the Dionex Ultimate 3,000 ultra-high performance liquid chromatography system, described above, with the atmospheric pressure chemical ionization probe in 
TABLE 1 | Life history parameters of gray and fin whales.

\begin{tabular}{|c|c|c|c|c|c|c|c|c|}
\hline Gray whale & Sex & Age & Status & Date & Location & Cause of death & Condition & Mass analyzed $\mathrm{mg}$ \\
\hline ER-19-01 & $\mathrm{M}$ & Calf & S & 1/26/2003 & California & Maternal Separation & Unknown & $50,150,400$ \\
\hline ER-19-05 & $\mathrm{M}$ & Calf & S & 5/18/2016 & California & Unknown & Unknown & 150,400 \\
\hline ER-19-06 & M & Neonate & $S$ & 1/17/1998 & California & Maternal separation & Mildly Underweight & 50,150 \\
\hline ER-19-07 & $\mathrm{F}$ & Adult & S & 8/16/2011 & California & Septicemia & Emaciated & $50,150,400$ \\
\hline ER-19-09 & $\mathrm{F}$ & Neonate & S & 1/01/1998 & California & Maternal separation & Moderately Underweight & $50,150,400$ \\
\hline ER-19-10 & $\mathrm{M}$ & Calf & S & 4/08/2000 & California & Enteritis/malnutrition & Emaciated & 50,150 \\
\hline ER-19-12 & M & Calf & S & 2/25/2001 & California & Maternal separation & Good & 50,150 \\
\hline ER-19-13 & $M$ & Adult & S & 4/19/2011 & California & Ship strike & Unknown & 150,400 \\
\hline ER-19-15 & $M$ & Juvenile & S & 6/20/2013 & California & Unknown & Unknown & $50,150,400$ \\
\hline ER-19-16 & $\mathrm{F}$ & Juvenile & $S$ & $10 / 22 / 2015$ & California & Malnutrition & Emaciated & 50,150 \\
\hline ER-19-17 & $\mathrm{F}$ & Juvenile & S & 3/12/2019 & California & Malnutrition & Emaciated & 50,150 \\
\hline ER-18-06 & M & Calf & $\mathrm{F}$ & 1/25/2018 & Baja California & Alive & Good & 50,150 \\
\hline ER-18-11 & $U$ & Calf & $\mathrm{F}$ & 1/25/2018 & Baja California & Alive & Good & 50,150 \\
\hline ER-18-15 & $U$ & Calf & $\mathrm{F}$ & 2/01/2018 & Baja California & Alive & Good & 50,150 \\
\hline ER-18-31 & $U$ & Calf & $\mathrm{F}$ & 3/19/2018 & Baja California & Alive & Good & 50,150 \\
\hline ER-18-33 & U & Calf & $\mathrm{F}$ & 3/20/2018 & Baja California & Alive & Good & 50,150 \\
\hline ER-18-34 & $U$ & Calf & $\mathrm{F}$ & $1 / 25 / 2018$ & Baja California & Alive & Good & 50,150 \\
\hline ER-18-35 & U & Adult & $\mathrm{F}$ & 3/21/2018 & Baja California & Alive & Good & 50 \\
\hline Fin whale & Sex & Age & Status & Date & Location & Cause of death & Condition & Mass analyzed mg \\
\hline BP-19-02 & $M$ & Subadult & S & 8/28/2015 & California & Ship strike & Good & $50,150,400$ \\
\hline BP-19-11 & $\mathrm{F}$ & Subadult & S & 1/07/2017 & California & Ship strike & Good & $50,150,400$ \\
\hline BP-19-14 & $\mathrm{M}$ & Juvenile & S & 8/19/2013 & California & Unknown & Good & $50,150,400$ \\
\hline BP-18-46 & $M$ & Adult & $\mathrm{F}$ & 6/01/2016 & Gulf of California & Alive & Good & 50 \\
\hline BP-18-66 & $\mathrm{M}$ & Adult & $\mathrm{F}$ & 6/04/2016 & Gulf of California & Alive & Good & 50 \\
\hline BP-18-76 & $M$ & Adult & $\mathrm{F}$ & 6/04/2016 & Gulf of California & Alive & Good & 50,150 \\
\hline BP-18-78 & $M$ & Adult & $\mathrm{F}$ & 9/17/2016 & Gulf of California & Alive & Good & 50,150 \\
\hline BP-18-91 & $M$ & Adult & $\mathrm{F}$ & 3/30/2017 & Gulf of California & Alive & Good & 50,150 \\
\hline BP-18-116 & $\mathrm{M}$ & Adult & $\mathrm{F}$ & 4/23/2017 & Gulf of California & Alive & Good & 50 \\
\hline
\end{tabular}

Abbreviations are $M$, male; F, female; $U$, unknown; $S$, stranded; $F$, free ranging.

negative ion mode. Mobile phases consisted of water and methanol. These three fin whale samples were only analyzed at $50 \mathrm{mg}$ due to limited tissue availability, therefore they were not included in the statistical analyses related to paired samples. Data analysis was done using Xcalibur software (Thermo Fisher Scientific). Positive hormone identification was achieved via two Multiple Reaction Monitoring transitions (Table 2 and Figure 1).

Method validation included standard curves for each hormone $(1,5,10,50,100,250$, and $500 \mathrm{ng} / \mathrm{mL})$. All calibration curves had an $R^{2} \geq 0.99$. The limit of detection (LOD) and limit of quantification (LOQ) were determined via $101 \mathrm{ng} / \mathrm{mL}$ injections of standards. The standard deviation of the measured steroid hormone concentration was multiplied by either the corresponding students $t$ critical value of 0.99 ( $t 0.99$ ) or by 10 for LOD and LOQ determination, respectively (Table 2). Ion suppression and matrix effects were determined by spiking blubber samples with an isotopically labeled standard (spiked final concentration $10 \mathrm{ng} / \mathrm{mL}$ ) before and after homogenization, respectively. Response was compared to a $10 \mathrm{ng} / \mathrm{mL}$ isotopically labeled standard. Relative standard deviation or precision (RSD) and recovery were determined using isotopically labeled hormone standards extracted with the sample. Each analytical run contained both method and solvent blanks to identify any background contamination. Concentrations were expressed in ng/g ww blubber.

\section{Sample Mass Comparison Study}

Minimum tissue mass requirement was investigated by comparing hormone detections and concentrations between paired 50 and $150 \mathrm{mg}$ ww blubber samples from gray $(n=15)$ and fin whales $(n=6)$ and between paired 150 and $400 \mathrm{mg}$ ww samples from gray $(n=9)$ and fin whales $(n=3)$. Tissue masses were selected to include those reported routinely in the literature for enzyme linked immunosorbent assay or LC-MS analysis. All paired samples were from the same blubber depth to ensure consistency. Animals for which paired samples did not exist, were not included.

\section{Stranded Versus Biopsy Comparison Study}

Possible correlations between corticosteroid concentrations in $50 \mathrm{mg}$ ww samples from stranded $(n=9)$ and free ranging $(n=7)$ gray whales were investigated. This was not investigated 
TABLE 2 | Analytical parameters for both isotopically labeled and non-labeled steroid hormones.

\begin{tabular}{|c|c|c|c|c|c|c|c|}
\hline Steroid & LOD (ng/g) & LOQ (ng/g) & Polarity & Precursor ION $(m / z)$ & Product ions $(\mathrm{m} / \mathrm{z})$ & Collision energy (V) & RF lens (V) \\
\hline \multirow[t]{2}{*}{ Aldosterone } & 3.72 & 12.4 & Negative & 359.15 & $188.84^{\star}$ & 18.95 & 140.73 \\
\hline & & & & & 331.13 & 16.77 & \\
\hline \multirow[t]{2}{*}{ Aldosterone $D_{8}$} & & & Negative & 366.06 & $194.03^{*}$ & 19.56 & 141.34 \\
\hline & & & & & 338.15 & 17.08 & \\
\hline \multirow[t]{2}{*}{ Androstenedione } & 0.38 & 1.25 & Positive & 287.23 & $97.06^{\star}$ & 21.12 & 130.41 \\
\hline & & & & & 109.06 & 22.94 & \\
\hline \multirow[t]{2}{*}{ Androstenedione ${ }^{13} \mathrm{C}$} & & & Positive & 290.24 & $100.04^{\star}$ & 21.22 & 135.57 \\
\hline & & & & & 112.06 & 23.50 & \\
\hline \multirow[t]{2}{*}{ Cortisol } & 1.15 & 3.83 & Positive & 363.24 & $121.06^{\star}$ & 23.55 & 149.22 \\
\hline & & & & & 327.10 & 15.26 & \\
\hline \multirow[t]{2}{*}{ Cortisol $\mathrm{D}_{4}$} & & & Positive & 367.23 & $121.04^{\star}$ & 23.95 & 156.20 \\
\hline & & & & & 331.10 & 15.81 & \\
\hline \multirow[t]{2}{*}{ Cortisone } & 0.84 & 2.8 & Positive & 361.21 & $121.06^{\star}$ & 28.10 & 156.50 \\
\hline & & & & & 163.11 & 23.25 & \\
\hline \multirow[t]{2}{*}{ Corticosterone } & 1.31 & 4.18 & Positive & 347.23 & $121.04^{\star}$ & 23.19 & 151.04 \\
\hline & & & & & 329.11 & 14.75 & \\
\hline \multirow[t]{2}{*}{$17 \beta$ estradiol } & 2.77 & 8.8 & Negative & 271.12 & $144.99^{\star}$ & 40.13 & 185.02 \\
\hline & & & & & 182.99 & 40.53 & \\
\hline \multirow[t]{2}{*}{$17 \beta$ estradiol ${ }^{13} \mathrm{C}$} & & & Negative & 274.02 & $147.99^{\star}$ & 40.18 & 134.05 \\
\hline & & & & & 186.00 & 40.33 & \\
\hline \multirow[t]{2}{*}{ Estrone } & 0.62 & 1.98 & Negative & 268.99 & $142.99^{\star}$ & 53.63 & 155.29 \\
\hline & & & & & 145.00 & 37.40 & \\
\hline \multirow[t]{2}{*}{ Estrone ${ }^{13} \mathrm{C}$} & & & Negative & 272.35 & $145.84^{\star}$ & 53.94 & 151.95 \\
\hline & & & & & 147.98 & 37.35 & \\
\hline \multirow[t]{2}{*}{$17 \alpha$ hydroxyprogesterone } & 0.74 & 2.46 & Positive & 331.26 & $97.04^{\star}$ & 23.60 & 153.77 \\
\hline & & & & & 109.06 & 26.03 & \\
\hline \multirow[t]{2}{*}{$17 \alpha$ hydroxyprogesterone ${ }^{13} \mathrm{C}$} & & & Positive & 334.26 & $100.04^{\star}$ & 24.06 & 158.32 \\
\hline & & & & & 112.04 & 26.18 & \\
\hline \multirow[t]{2}{*}{ Progesterone } & 0.40 & 1.34 & Positive & 315.26 & $97.04^{\star}$ & 20.82 & 144.67 \\
\hline & & & & & 109.04 & 23.55 & \\
\hline \multirow[t]{2}{*}{ Progesterone ${ }^{13} \mathrm{C}$} & & & Positive & 318.30 & $100.04^{\star}$ & 21.17 & 146.79 \\
\hline & & & & & 112.04 & 23.95 & \\
\hline \multirow[t]{2}{*}{ Testosterone } & 0.54 & 1.80 & Positive & 289.26 & $97.06^{\star}$ & 21.42 & 157.71 \\
\hline & & & & & 109.04 & 23.19 & \\
\hline \multirow[t]{2}{*}{ Testosterone ${ }^{13} \mathrm{C}$} & & & Positive & 292.27 & $100.04^{\star}$ & 21.83 & 141.94 \\
\hline & & & & & 112.04 & 24.41 & \\
\hline
\end{tabular}

Product ions represent both the quantifier ion (indicated by *) and qualifier ion.

in fin whales as two of the three stranded animals were killed by ship strike.

\section{Statistical Analyses}

Analyses were conducted in Minitab (versions 18 and 19), JMP Pro (version 14), and R (version 1.2.5042, packages: cplm and matrix) with alpha set to 0.05 . Hormone concentrations between paired samples were compared using Tweedie's compound Poisson mixed model in $\mathrm{R}$ which accounted for paired, continuous, zero inflated data (Pellegrini et al., 2017). Precision values across species and cortisol concentrations between stranded and non-stranded animals were compared with a twosample $t$-test. Detection incidence in differing masses of paired samples were compared with a Fisher's exact test. A Kendall's $\tau$ was used to determine whether correlations existed among hormones. Minimum spiking concentrations between matrices were compared with a Mann Whitney $U$-test (data was not normally distributed).

\section{RESULTS}

\section{Tissue Homogenization Optimization Study}

Homogenization of gray whale blubber via bead beating resulted in suitable RSD and recovery values in downstream hormone analysis while homogenization via blade dispersion resulted in lower recovery and, for most hormones, RSD beyond the acceptable limit of $20 \%$ or less (Figure 2). Recovery of analytes from samples homogenized via blade dispersion decreased 


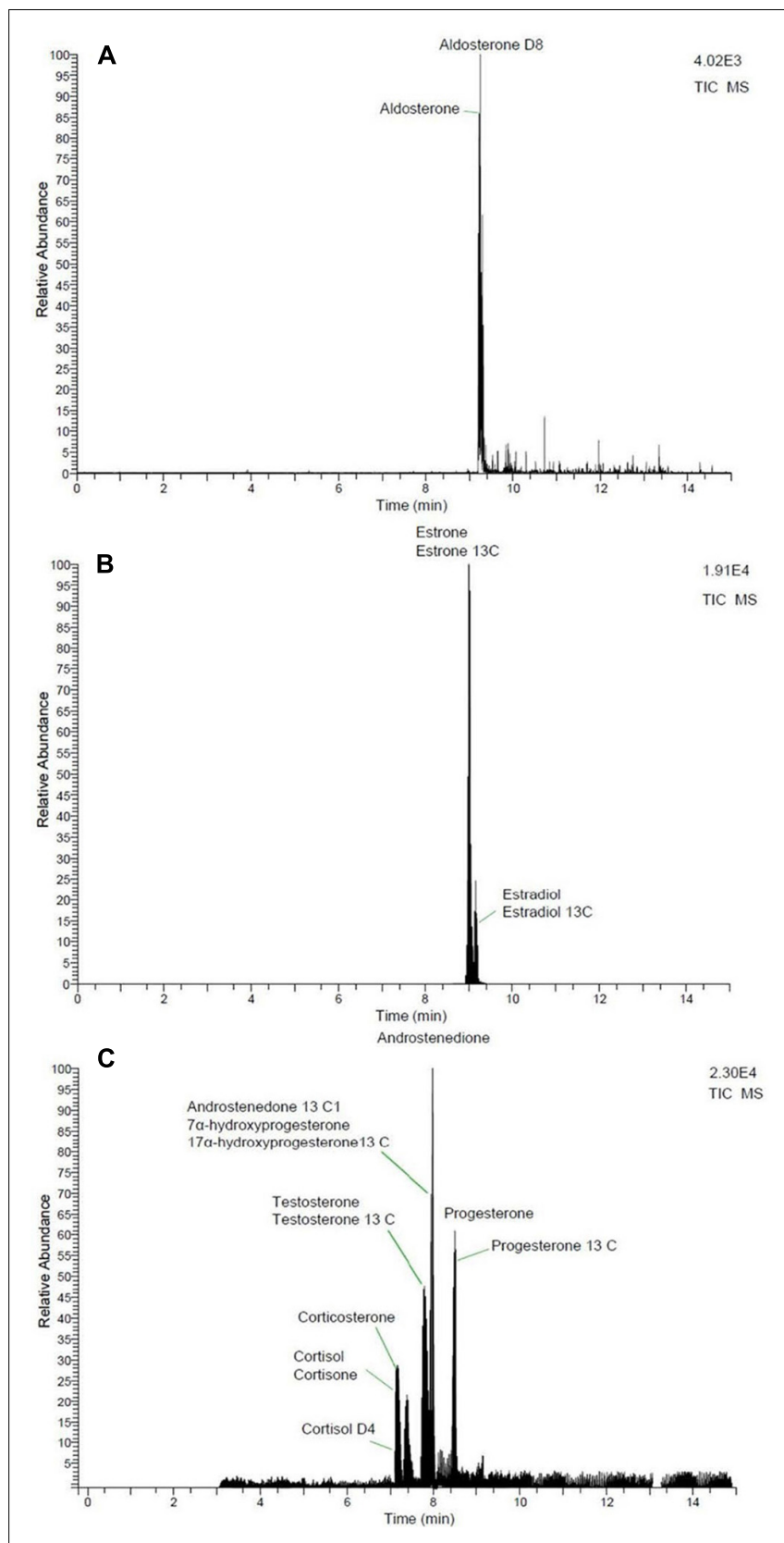

FIGURE 1 | Total ion chromatograms of hormones. (A) Aldosterone, (B) estrogens, and (C) corticosteroids, progestogens, and androgens.

considerably for androstenedione 13C (61\% bead, 35\% blade), $17 \beta$-estradiol 13C (68\% bead, 31\% blade), estrone 13C (68\% bead, $30 \%$ blade), and $17 \alpha$-hydroxyprogesterone $13 \mathrm{C}(62 \%$ bead, 39\% blade), and slightly for cortisol D4 (79\% bead, 68\% blade) and testosterone 13C (56\% bead, $43 \%$ blade), while it increased slightly for progesterone 13C (50\% bead, 69\% blade). In samples homogenized via blade dispersion, precision values were within the acceptable limit only for androstenedione 13C and $17 \alpha$-hydroxyprogesterone $13 \mathrm{C}$ and increased by two and a half to sixfold for all other hormones. Fin whale samples homogenized via blade dispersion were too lipid rich for LC-MS/MS analysis but suitable when homogenized via bead beating.

\section{Liquid Chromatography Tandem Mass Spectrometry Method Validation}

In both species, ion suppression was either not apparent or minimal $(\leq 20 \%)$. Recovery and RSD for all samples homogenized via bead beating were within Environmental Protection Agency limits for both gray (50-70\% recovery, 12.57$19.37 \%$ RSD) and fin (59-72\% recovery, 4.3-16\% RSD) whale matrices (Figure 2). RSD differed significantly between species $(n=7, p<0.001)$; but neither did recovery $(n=7, p>0.05)$ nor optimal spiking concentrations $(n=7, p>0.05)$. Based on recovery and $\mathrm{RSD}$, our methodology was accurate and precise in the measurement of spiked known quantities for all 10 hormones, confirming the methodology capabilities at that tissue mass.

\section{Sample Mass Comparison Study}

Steroid hormones were detected in fourteen $50 \mathrm{mg}$ and fifteen $150 \mathrm{mg}$ ww paired gray whale samples ( $n=15$, Figures 3, 4 and Table 3). There were no significant differences in detections of androstenedione $(n=3, n=3)$, cortisol $(n=10, n=8)$, cortisone ( $n=4, n=5)$, or $17 \alpha$-hydroxyprogesterone $(n=4, n=5)$ between the 50 and $150 \mathrm{mg}$ ww paired samples, respectively (Figure 3). Cortisol concentrations were significantly higher in $50 \mathrm{mg} \mathrm{ww}$ (mean $4 \mathrm{ng} / \mathrm{g}$, range $1-20 \mathrm{ng} / \mathrm{g}$ ) than $150 \mathrm{mg}$ ww samples (mean $17.2 \mathrm{ng} / \mathrm{g}$, range 10.0-62.6 ng/g), but there were no significant differences in concentrations of androstenedione, cortisone, or $17 \alpha$-hydroxyprogesterone (Figure 4). Low detection incidence for the remaining hormones precluded comparison.

Steroid hormones were detected in six $150 \mathrm{mg}$ and six 400 mg ww paired gray whale blubber samples $(n=8$, Table 3$)$. There were no significant differences in cortisol detection rates between the 150 and $400 \mathrm{mg}$ ww paired samples $(n=3, n=4)$. Low detection incidence for the remaining hormones (Figure 3) precluded comparison. There were no significant differences in cortisol and $17 \alpha$-hydroxyprogesterone concentrations between 150 and $400 \mathrm{mg}$ ww paired samples (Figure 4). Concentration differences in other hormones precluded comparison.

Steroid hormones were detected in four $50 \mathrm{mg}$ and five $150 \mathrm{mg}$ ww paired fin whale samples homogenized via bead beating ( $n=6$, Figure 3 and Table 4). There were no significant differences in androstenedione detection incidence $(n=4$, $n=4)$. The low detection incidence of androstenedione, cortisol, $17 \alpha$-hydroxyprogesterone, and testosterone precluded analysis. Hormones were detected in all 150 and $400 \mathrm{mg}$ ww paired fin whale samples ( $n=3$, Figure 3 and Table 4). Androstenedione concentrations were statistically similar between masses, but low detection incidences precluded statistical analyses for cortisol and $17 \alpha$-hydroxyprogesterone.

\section{Overall Hormone Detection and Correlations in $50 \mathrm{mg}$ Wet Weight Blubber Samples}

All samples were analyzed using $50 \mathrm{mg}$ ww blubber mass. Aldosterone, androstenedione, cortisol, cortisone, $17 \beta$-estradiol, 

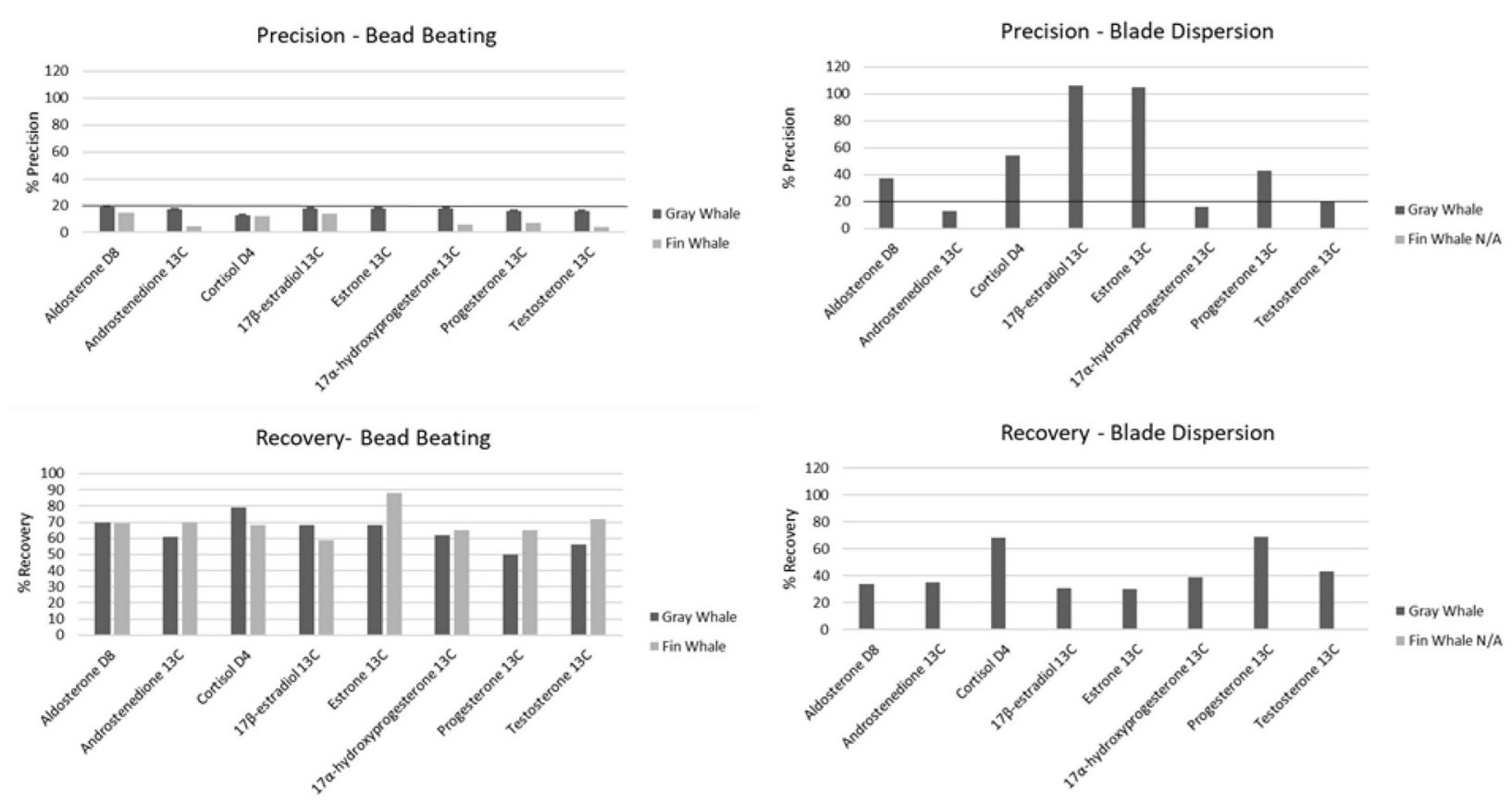

FIGURE 2 | Precision \% and recovery values obtained with bead beating (Fast Prep 24) and blade dispersion (Polytron) homogenization methods ( $\mathrm{n}=7$ ). Line represents the $20 \%$ cut off value for precision.

estrone, $17 \alpha$-hydroxyprogesterone, progesterone, and testosterone were detected in gray whale blubber (Table 3). Androstenedione, cortisol, corticosterone, 17 $\beta$-estradiol, $17 \alpha$-hydroxyprogesterone, and testosterone were detected in fin whale blubber (Table 4).

A significant positive correlation $(p<0.01)$ was observed between cortisol and cortisone in all four $50 \mathrm{mg}$ gray whale blubber samples where both hormones were detected and with the former in higher concentration $(3 \mathrm{x}-5 \mathrm{x})$. Cortisol was detected in 10 gray whales with some concentration overlap in the stranded and free ranging groups but significantly higher concentrations in stranded individuals $(p<0.05)$. No other significant hormone correlations were observed in either species.

\section{DISCUSSION}

\section{Blubber Homogenization Methodology Influences Downstream Analyses}

Blubber homogenization via bead beating was greatly superior to blade dispersion. RSD for both species indicated that bead beating was suitable for all samples while blade dispersion was only acceptable in $25 \%$ of gray whale samples and none of the fin whale samples. Bead beating was more time efficient ( $45 \mathrm{~min} / 24$ samples) than blade dispersion ( $75 \mathrm{~min} /$ sample). We hypothesize that the generally poor blade dispersion homogenization RSD values were due to remaining intact fat cells in the homogenates. This is supported by the fact that fin whale samples homogenized via blade dispersion were too lipid rich for LC-MS/MS analysis (at the hexane step, the supernatants displayed foam and cloudiness due to leftover lipid content. Final extracts contained visible fat), whereas bead beating-homogenized samples from the same animals were suitable. In the literature, both blubber homogenization methods have been reported with bead beating preferred in conjunction with LC-MS/MS (Boggs et al., 2017; Hayden et al., 2017; Galligan et al., 2020). This is the first report on the influence of blubber homogenization methodology on downstream LC-MS/MS analyses in these species.

\section{Gray Whale Blubber Hormone Profiles}

Our results validated our methodology for simultaneous detection of multiple hormones in $50 \mathrm{mg}$ ww of gray whale blubber. To the best of our knowledge, we are the first to report, androstenedione, cortisone, estrone, and $17 \alpha$-hydroxyprogesterone concentrations in any gray whale matrix and aldosterone, 17 $\beta$-estradiol, and corticosterone concentrations in gray whale blubber. Hunt et al. (2017) had previously reported aldosterone, 17 $\beta$-estradiol, and corticosterone concentrations in gray whale baleen. All hormone detections occurred in $50 \mathrm{mg}$ ww samples except for corticosterone which was detected in two $150 \mathrm{mg}$ ww samples. While endogenous corticosterone was not detected in $50 \mathrm{mg}$ gray whale blubber, our methodology was accurate and precise in the measurement of spiked known quantities, confirming the methodology capabilities at that tissue mass. We previously detected cortisol, progesterone, and testosterone in gray whale blubber with a different LC-MS methodology (Hayden et al., 2017). Steroid hormone concentrations detected in $50 \mathrm{mg}$ ww gray whale samples are provided below along with information related to blubber hormone detection in other cetacean species. 

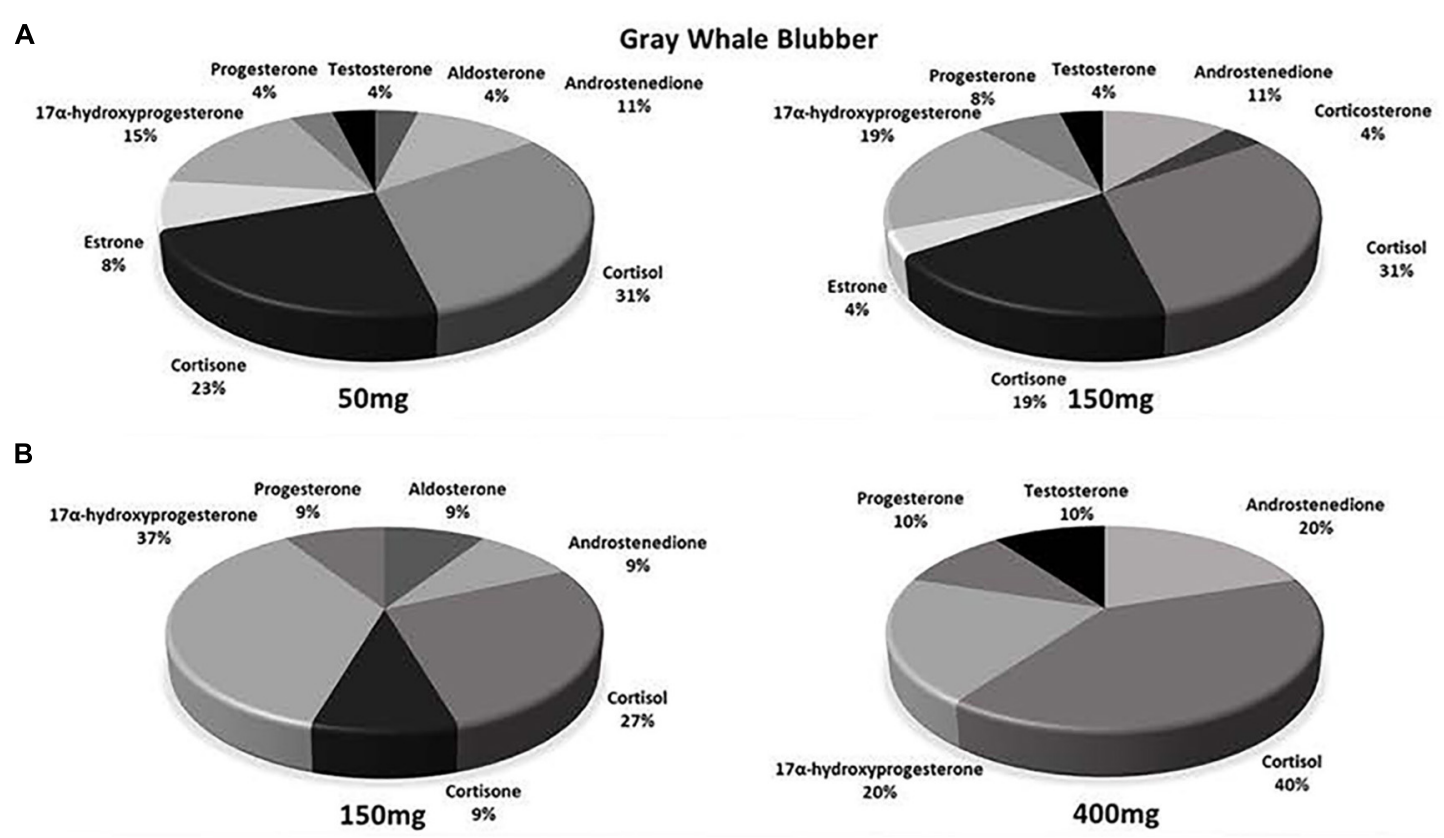

C

Fin Whale Blubber
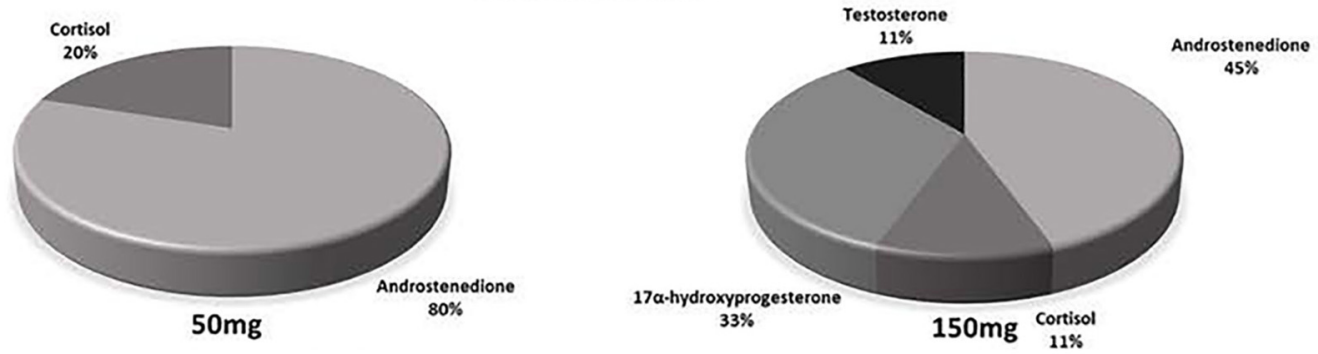

D

$17 \alpha$-hydroxyprogesterone
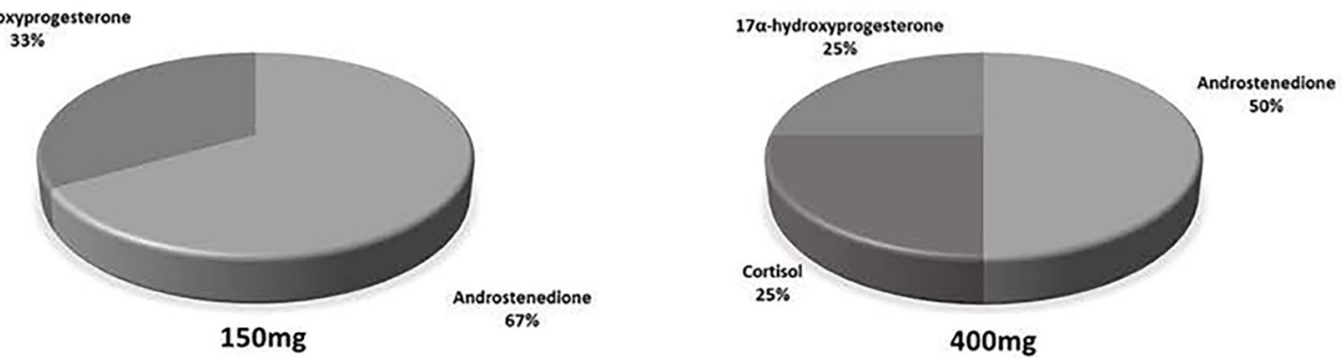

FIGURE 3 | Hormone detection profiles in 50, 150, and $400 \mathrm{mg}$ ww paired blubber samples in gray and fin whales. (A) $n=15$, (B) $n=6$, (C) $n=6$, and (D) $n=3$. Percentages correspond to the proportion of samples where hormones were detected in relation to all samples within panel and mass category.

Here, we put the concentrations we detected in the context of previously reported hormone blubber concentrations in other cetaceans. We acknowledge that such comparisons are mainly for the purpose of illustrating that concentrations obtained with our methodology are within, or close to, ranges previously reported in cetacean blubber and that further research is needed where demographic trends are known before hormonal trends can be elucidated in the gray whale. In free ranging gray whales $(n=7)$, mean cortisol concentration was $2.8 \mathrm{ng} / \mathrm{g}(<1.2-15.1$ $\mathrm{ng} / \mathrm{g}$ ) which is similar to those reported from free ranging blue whales Balaenoptera musculus, 1.4-5.6 ng/g, (Atkinson et al., 2020), but lower than reported in humpback whales (Megaptera novaeangliae, $14.9-61.5 \mathrm{ng} / \mathrm{g}$, Teerlink et al., 2018; 0.20-61.62 ng/g, Mingramm et al., 2020). In stranded gray whales $(n=9)$, mean cortisol concentration was $34 \mathrm{ng} / \mathrm{g}(<1.2-75.1 \mathrm{ng} / \mathrm{g})$ which was higher than in stranded dolphins (mean $24.3 \mathrm{ng} / \mathrm{g}$, Kellar et al., 2015) and stranded humpback whales (mean $5.2 \mathrm{ng} / \mathrm{g}$, Dalle Luche et al., 2019). Concentrations of cortisone (8.8-14.1 ng/g) were higher than those reported in stressed bottlenose dolphins (Tursiops truncates) and stranded humpback whales (mean 1.7 
A

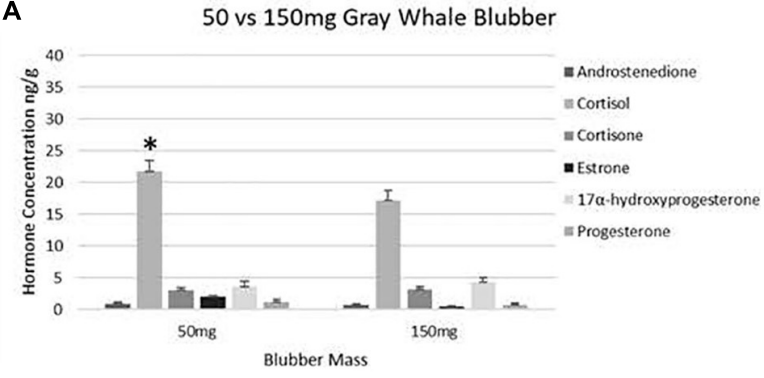

C

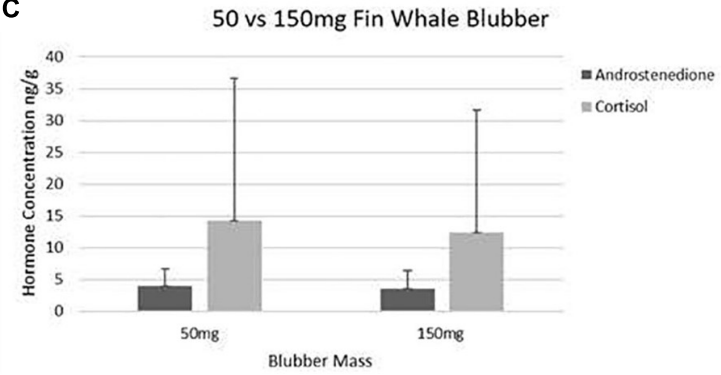

B

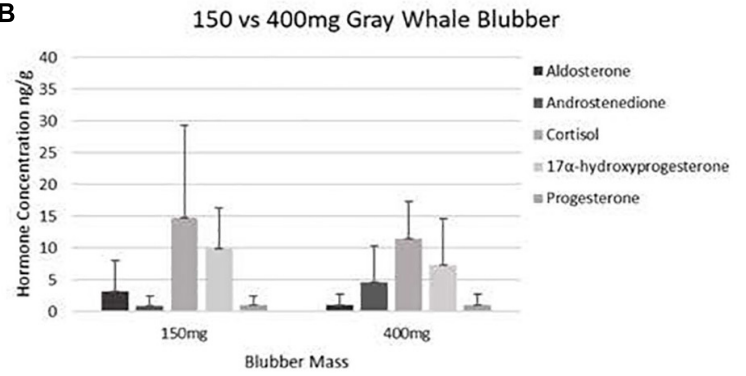

D

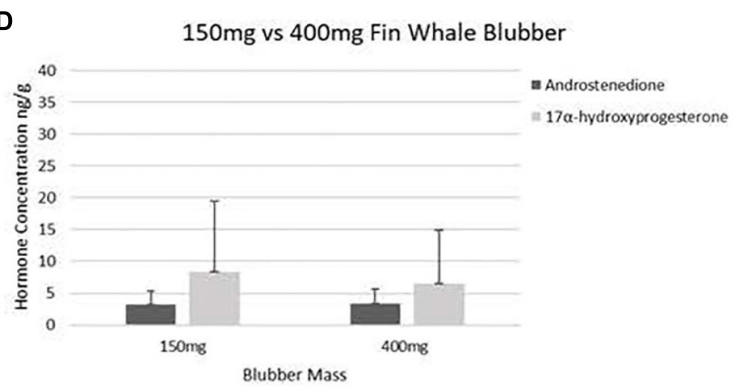

FIGURE 4 | Mean concentrations of hormones in paired blubber samples of gray and fin whales. Steroid hormone concentration comparisons between paired gray whale (A) $(n=15)$, (B) $(n=6)$, and fin whale (C) $(n=6)$, and (D) $(n=3)$ blubber masses ww. Concentrations below the LOD were designated as "zeros". Hormones for which all data was below the LOD are not shown. An * indicates significance $(p<0.05)$.

ng/g, Dalle Luche et al., 2019; 0.3-2.3 ng/g, Galligan et al., 2020). Aldosterone was detected in a single stranded juvenile female, ER-19-16 (40.7 ng/g). Cortisol and cortisone were positively correlated whenever both were detected, as previously observed in other cetaceans (Boggs et al., 2019; Dalle Luche et al., 2019). Metabolism of steroids occurs in mammalian skin and evidence suggests cortisol and cortisone are indeed metabolized in marine mammal blubber (Kershaw and Hall, 2016; Galligan et al., 2018; Dalle Luche et al., 2019).

Estrone was only detected in calves $(1.1-31.0 \mathrm{ng} / \mathrm{g}$, mean $16 \mathrm{ng} / \mathrm{g})$. In ER-18-06 (31.0 ng/g) the estrone concentration exceeded those reported in humpback whales $(<0.1-6.54 \mathrm{ng} / \mathrm{g}$, Dalle Luche et al., 2019). Additionally, $17 \alpha$-hydroxyprogesterone (13.8-39.8 ng/g, mean $26.76 \mathrm{ng} / \mathrm{g}$ ) was detected in higher concentrations in both an adult female, ER-18-34 (13.8 ng/g) and an unsexed calf, ER-18-33 (39.8 ng/g) than in free ranging, live-captured, or stranded bottlenose dolphins $(<0.1-3.16 \mathrm{ng} / \mathrm{g}$, Boggs et al., 2017; 0-4.64 ng/g, Galligan et al., 2019; 1.6-13.7 ng/g, Galligan et al., 2020) and humpback whales $(<0.5-$ $1.87 \mathrm{ng} / \mathrm{g}$, Dalle Luche et al., 2019). Testosterone (3 ng/g) was detected only in one unsexed calf, ER-18-31, at a similar concentration reported for a juvenile gray whale male using LC/MS methodology (Hayden et al., 2017) but greater than mean concentrations observed at any life stage in gray whale males using immunoassays (Melica et al., 2021). No adult males were analyzed at the $50 \mathrm{mg}$ ww mass, and our sample set did not include any breeding adult males, known in gray whales and other species for expressing higher concentrations (Boggs et al., 2019; Galligan et al., 2019; Melica et al., 2021).

Dalle Luche et al. (2020) reported that high androstenedione concentrations $(7.8-40 \mathrm{ng} / \mathrm{g})$ may indicate late term pregnancy in humpback whales. In our sample set, only one stranded juvenile female, ER-19-16, had an androstenedione concentration within that range $(8.68 \mathrm{ng} / \mathrm{g})$. Whether androstenedione could indicate certain pregnancy stages in gray whales is currently unknown and further research is warranted. Progesterone was detected in a non-pregnant, adult female, ER-19-07 (18.8 ng/g) also presenting with the second highest cortisone and the third highest cortisol concentration in our sample set. The animal died after swimming in fresh water for 54 days. Dalle Luche et al. (2019) reported a correlation between cortisol, cortisone, and progesterone in non-pregnant, stranded humpback whales, indicating elevated progesterone concentrations may reflect a poor physiological state. More research is warranted in the gray whale. A valuable probability model for gray whale pregnancy was recently developed using blubber progesterone concentrations detected by immunoassays (Melica et al., 2021). Melica's model exhibits a strong fit for known pregnant and non-pregnant whales and higher uncertainties for whales with intermediate progesterone concentrations. ER-19-07 would have been classified as more likely pregnant, warranting further investigation into the causal relationship between stress and elevated progesterone levels in cetaceans and the establishment of multiple hormone markers specific to various reproductive stages in gray whales. This highlights the relevance of multiple steroid hormone panels.

\section{Fin Whale Blubber Hormone Profiles}

To the best of our knowledge, we are the first to report on $17 \alpha$-hydroxyprogesterone in the fin whale. Androstenedione, cortisol, corticosterone, $17 \beta$-estradiol, $17 \alpha$-hydroxyprogesterone, and testosterone were detected in $50 \mathrm{mg}$ samples. Both $17 \alpha$-hydroxyprogesterone and testosterone were detected in the 
TABLE 3 | Hormone panel in 50, 150, and 400 mg gray whale samples.

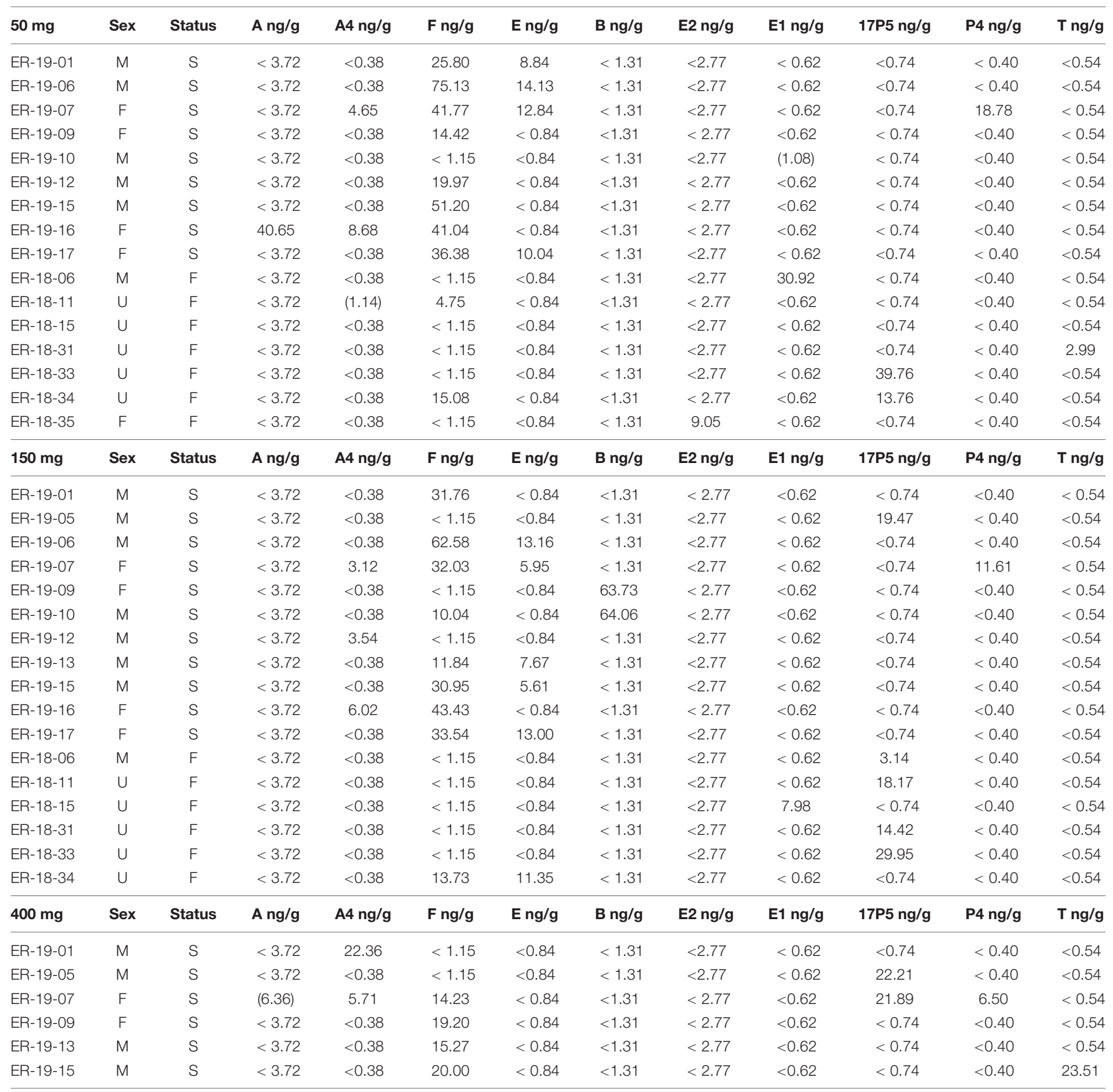

$F, M$, and $U$ correspond to female, male, and unknown, respectively. $S$ and $F$ correspond to stranded and free ranging, respectively. Hormone abbreviations are $A$ (aldosterone), A4 (androstenedione), F(cortisol), E (cortisone), B (corticosterone), E2 (17ß-estradiol), E1 (estrone), P4 (progesterone), T (testosterone). Data in parentheses indicate values above $L O D$ but below $L O Q$.

unpaired $50 \mathrm{mg}$ ww fin whale samples. While endogenous aldosterone, cortisone, estrone, and progesterone were not detected in fin whale blubber, our methodology was accurate and precise in the measurement of spiked known quantities within the matrix, confirming the methodology capabilities. Concentrations detected in $50 \mathrm{mg}$ ww fin whale samples are provided below along with information related to blubber hormone detection in other species.
In fin whales, cortisol $(85.71 \mathrm{ng} / \mathrm{g})$ was detected in a single, stranded juvenile male, BP-19-14. Cortisol concentrations were higher than in stressed bottlenose dolphin $(<0.1-21.0 \mathrm{ng} / \mathrm{g}$, Galligan et al., 2020), and humpback whale blubber samples (14.9-61.5 ng/g, Teerlink et al., 2018; < 0.1-85.1 ng/g, Dalle Luche et al., 2019; 0.20-61.62 ng/g, Mingramm et al., 2020). Androstenedione was the most commonly detected hormone (five males out of nine males and one female, 2.53-10.42 ng/g) 
TABLE 4 | Hormone panel in 50, 150, and 400 mg fin whale samples F, M, and U correspond to female, male, and unknown, respectively.

\begin{tabular}{|c|c|c|c|c|c|c|c|c|c|c|c|c|}
\hline $50 \mathrm{mg}$ & Sex & Status & A ng/g & A4 ng/g & F ng/g & E ng/g & B ng/g & E2 ng/g & E1 ng/g & 17P5 ng/g & P4 ng/g & T ng/g \\
\hline BP-19-02 & $M$ & S & $<3.72$ & 7.63 & $<1.15$ & $<0.84$ & $<1.31$ & $<2.77$ & $<0.62$ & $<0.74$ & $<0.4$ & $<0.54$ \\
\hline BP-19-11 & $\mathrm{F}$ & $S$ & $<3.72$ & $<0.38$ & $<1.15$ & $<0.84$ & $<1.31$ & $<2.77$ & $<0.62$ & $<0.74$ & $<0.4$ & $<0.54$ \\
\hline BP-19-14 & $M$ & S & $<3.72$ & 10.42 & 85.71 & $<0.84$ & $<1.31$ & $<2.77$ & $<0.62$ & $<0.74$ & $<0.4$ & $<0.54$ \\
\hline BP-18-46 & $M$ & $\mathrm{~F}$ & $<3.72$ & 2.74 & $<1.15$ & $<0.84$ & $<1.31$ & 11.66 & $<0.62$ & 22.68 & $<0.4$ & 8.45 \\
\hline BP-18-66 & $M$ & $\mathrm{~F}$ & $<3.72$ & $<0.38$ & $<1.15$ & $<0.84$ & 80.46 & 9.61 & $<0.62$ & 18.185 & $<0.4$ & $<0.54$ \\
\hline BP-18-76 & $M$ & $\mathrm{~F}$ & $<3.72$ & 2.72 & $<1.15$ & $<0.84$ & $<1.31$ & $<2.77$ & $<0.62$ & $<0.74$ & $<0.4$ & $<0.54$ \\
\hline BP-18-78 & $M$ & $\mathrm{~F}$ & $<3.72$ & 2.53 & $<1.15$ & $<0.84$ & $<1.31$ & $<2.77$ & $<0.62$ & $<0.74$ & $<0.4$ & $<0.54$ \\
\hline BP-18-91 & $M$ & $\mathrm{~F}$ & $<3.72$ & $<0.38$ & $<1.15$ & $<0.84$ & $<1.31$ & $<2.77$ & $<0.62$ & $<0.74$ & $<0.4$ & $<0.54$ \\
\hline BP-18-116 & $M$ & $\mathrm{~F}$ & $<3.72$ & $<0.38$ & $<1.15$ & $<0.84$ & $<1.31$ & 9.60 & $<0.62$ & 18.49 & $<0.4$ & $<0.54$ \\
\hline $150 \mathrm{mg}$ & Sex & Status & A ng/g & A4 ng/g & F ng/g & E ng/g & B ng/g & E2 ng/g & E1 ng/g & 17P5 ng/g & P4 ng/g & $\mathrm{T}$ ng/g \\
\hline BP-19-02 & $M$ & S & $<3.72$ & 5.35 & $<1.15$ & $<0.84$ & $<1.31$ & $<2.77$ & $<0.62$ & $<0.74$ & $<0.4$ & 5.93 \\
\hline BP-19-11 & $\mathrm{F}$ & S & $<3.72$ & $<0.38$ & $<1.15$ & $<0.84$ & $<1.31$ & $<2.77$ & $<0.62$ & 25.20 & $<0.4$ & $<0.54$ \\
\hline BP-19-14 & $M$ & S & $<3.72$ & 4.41 & $<1.15$ & $<0.84$ & $<1.31$ & $<2.77$ & $<0.62$ & $<0.74$ & $<0.4$ & $<0.54$ \\
\hline BP-18-76 & $M$ & $\mathrm{~F}$ & $<3.72$ & 2.15 & $<1.15$ & $<0.84$ & $<1.31$ & $<2.77$ & $<0.62$ & $<0.74$ & $<0.4$ & $<0.54$ \\
\hline BP-18-78 & $\mathrm{M}$ & $\mathrm{F}$ & $<3.72$ & 2.72 & $<1.15$ & $<0.84$ & $<1.31$ & $<2.77$ & $<0.62$ & $<0.74$ & $<0.4$ & $<0.54$ \\
\hline BP-18-91 & $M$ & $\mathrm{~F}$ & $<3.72$ & $<0.38$ & $<1.15$ & $<0.84$ & $<1.31$ & $<2.77$ & $<0.62$ & 17.32 & $<0.4$ & $<0.54$ \\
\hline $400 \mathrm{mg}$ & Sex & Status & A ng/g & A4 ng/g & F ng/g & E ng/g & B ng/g & E2 ng/g & E1 ng/g & 17P5 ng/g & P4 ng/g & $\mathrm{T} \mathbf{n g} / \mathrm{g}$ \\
\hline BP-19-02 & $M$ & S & $<3.72$ & 5.77 & $<1.15$ & $<0.84$ & $<1.31$ & $<2.77$ & $<0.62$ & $<0.74$ & $<0.4$ & $<0.54$ \\
\hline BP-19-11 & $\mathrm{F}$ & S & $<3.72$ & $<0.38$ & $<1.15$ & $<0.84$ & $<1.31$ & $<2.77$ & $<0.62$ & 19.34 & $<0.4$ & $<0.54$ \\
\hline BP-19-14 & $M$ & $S$ & $<3.72$ & 4.41 & 32.18 & $<0.84$ & $<1.31$ & $<2.77$ & $<0.62$ & $<0.74$ & $<0.4$ & $<0.54$ \\
\hline
\end{tabular}

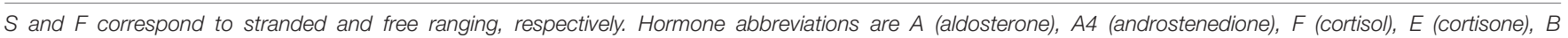

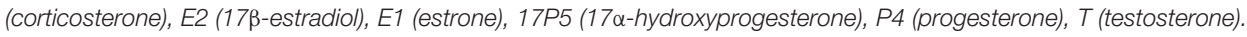

exhibiting concentrations falling within ranges reported for free ranging, live captured, and stranded bottlenose dolphins $(<0.1-$ $15.2 \mathrm{ng} / \mathrm{g}$, Boggs et al., 2017; 0-19.0 ng/g, Galligan et al., 2019; 3.5-63.3 ng/g, Galligan et al., 2020) and humpback whales ( $<0.15-88$ ng/g, Dalle Luche et al., 2019, 2021). Concentrations of $17 \alpha$-hydroxyprogesterone (18.19-22.68 ng/g) were higher than those reported in humpback whales $(<0.5-1.87 \mathrm{ng} / \mathrm{g}$, Dalle Luche et al., 2019) and fell within the range reported in free ranging, live captured, and stranded bottlenose dolphins $(<0.1-$ 3.16 ng/g, Boggs et al., 2017; 0-4.64 ng/g, Galligan et al., 2019; 1.6-13.7 ng/g, Galligan et al., 2020). Finally, testosterone (8.45 $\mathrm{ng} / \mathrm{g}$ ) was detected in an adult male and fell within concentrations reported for fin whale males of unknown age (0.05-14.22 ng/g, Carone et al., 2019). Although the above comparisons with other species are useful, further research, taking into account life parameters, is needed to elucidate species specific and possible sex specific hormone concentrations indicative of reproductive and stress status in the fin whale.

\section{Implications of Differences in Blubber Matrices Between Species}

There were no significant differences in recovery or optimal spiking concentrations between species, but RSD varied significantly ( $n=7$ for each species, $p<0.001$ ). Cetacean blubber composition, including lipid content and fatty acid composition, can differ according to geographical location, season, nutritive condition, species, and other factors (Krahn et al., 2001; Ruchonnet et al., 2006; Koopman, 2007). Difference in the matrix composition between gray and fin whales may thus explain the significantly different RSD values observed. Based on these results, we recommend that a precision analysis be performed on species-specific matrix, and ideally from study-specific matrix, rather than a reference standard species matrix unless both species have similar composition. This is important for appropriate calibration and optimization prior to sample analyses.

\section{Importance of Minimal Tissue Mass and Sensitivity}

Our methodology can detect hormone concentrations in the low ng/g range. In two recent publications that used a more expensive and sensitive instrument, the percentage of humpback whales or bottlenose dolphins with hormone concentrations only in $\mathrm{pg} / \mathrm{g}$ range (which is outside the sensitivity of our methodology) were $0-50 \%$ for androstenedione, $10-75 \%$ for cortisol, $10 \%$ for cortisone, $20 \%$ for corticosterone, $10 \%$ for estradiol, $30 \%$ for estrone, $0-10 \%$ for hydroxyprogesterone, $50-$ $66 \%$ for progesterone, and $0-30 \%$ for testosterone (Boggs et al., 2017; Dalle Luche et al., 2019). Whether these percentages reflect what could be expected in the gray whale samples included in this study is currently unknown, nonetheless, a ng/g sensitivity range was clearly sufficient to detect multiple hormones and suitable for gray whale pregnancy detection (Melica et al., 2021).

The reduction of tissue mass is critical in protected species research where both sample access and size are limited. Another possible benefit was highlighted in studies reporting cortisol extraction efficiency decreasing significantly with blubber mass 
above 200 mg ww (Kershaw and Hall, 2016; Kershaw et al., 2017). Kershaw and Hall (2016) suggested that larger sample mass could result in poorer homogenization of tissue. Upon visual inspection, our tissue homogenates looked identical between sample masses however it is still possible that minute differences did, indeed, exist. If this was the case, it could explain the lower cortisol concentrations detected in the larger tissue masses. Further research is warranted. Our method uses instrumentation commonly found in most mass spectrometry laboratories, for example, routinely present in university chemistry and biochemistry departments as well as industry chemical labs and is the first to report on a full hormone panel optimized for small tissue masses (two-16 times less than reported in the literature), (Boggs et al., 2017; Dalle Luche et al., 2019, 2021; Galligan et al., 2020). Apart from cortisol found in higher concentrations in $50 \mathrm{mg}$ ww than in $150 \mathrm{mg}$ ww samples, the results of the mass comparison study in the gray whale showed no significant differences in concentrations or detection rates between sample mass examined. Based on these results, a mass of $50 \mathrm{mg} \mathrm{ww}$ of blubber is suitable for hormone analysis in the gray whale and likely suitable for steroid hormone analysis in the fin whale. It should be noted that we detected fewer steroid hormone concentrations in the $\mathrm{ng} / \mathrm{g}$ range in the fin whale samples than the gray whale samples. However, the sample size of fin whale tissue was also smaller than the sample size of gray whale tissue. The methodology presented here illustrates that a small $50 \mathrm{mg}$ ww blubber mass and a ng/g sensitivity are robust enough to greatly benefit stress and reproductive steroid hormone analysis and monitoring in cetaceans, particularly in common situations where tissue is limited.

\section{Glucocorticoid Concentrations in Free Ranging and Stranded Gray Whales}

Stranded animals $(n=7)$ generally had higher concentrations of glucocorticoids in their blubber than free ranging animals $(n=9)$, as observed in humpback and north Atlantic right whales (Eubalaena glacialis) (Mingramm et al., 2020; Graham et al., 2021). All free ranging gray whales in the study were visually categorized in good body condition. Cortisone was only detected in stranded animals $(n=4)$ and with concentrations ranging from $8.8 \mathrm{ng} / \mathrm{g}$ to $14.1 \mathrm{ng} / \mathrm{g}$. Thus, the presence of cortisone in concentrations within and above this range might be indicative of stress in gray whales. Due to the small sample size, however, further research is warranted. Cortisol was detected in ten whales with some concentration overlap in the stranded and free ranging groups but significantly higher concentrations in stranded individuals. Only one stranded whale, ER-19-10, had a cortisol concentration $\leq 14.2 \mathrm{ng} / \mathrm{g}$ (mean in free ranging animals $+2 \mathrm{SD}$ ) and only one free ranging gray whale, ER-18-34, had a cortisol concentration $\geq 14.2 \mathrm{ng} / \mathrm{g}$. While there was not a clear gap in concentrations between stranded and free ranging animals, $89 \%$ of the stranded gray whales presented with cortisol concentrations $\geq 14.2 \mathrm{ng} / \mathrm{g}$ and $78 \%$ presented with cortisol concentrations $\geq 19.9 \mathrm{ng} / \mathrm{g}$ (mean in free ranging animals $+3 \mathrm{SD}$ ). This trend indicates that the future establishment of stress thresholds may be possible, however a larger sample size is required. Similar threshold calculation techniques have previously been considered in marine mammal health assessments (Wittmaack et al., 2015). While free ranging ER-18-34 had good body condition, it is possible that it experienced stress that had not affected body condition at the time of sampling (e.g., predation, recent food shortage). Further research is warranted to determine whether stress could indeed be detected via hormone analysis before poor body condition is observable.

While a greater sample size is needed to confirm, our results suggest that hormone analyses might be suitable to detect stress in gray whales and complement other existing measures of health, such as body condition. Gray whale body condition (Lemos et al., 2020a; Christiansen et al., 2021), together with hormone analysis, could further our understanding of the potential relationship between high blubber corticosteroid concentrations and fitness, overall reproductive health, and survival. Stress hormones have been monitored as part of population health assessments in smaller cetaceans, such as bottlenose dolphins (Fair et al., 2014; Schwacke et al., 2014; Barratclough et al., 2019). Such hormone analyses are valuable for all cetaceans and may prove particularly useful in identifying the scope of potential stress response during and following unusual mortality events (UMEs), oil spills, severe weather, ship traffic interaction, seismic or sonar disturbance, fishing gear entanglement or other challenging events. For example, the Gray Whale UME \#68, has been linked to the mortality (at the time of writing) of 497 individuals off North America. To date, while some of the stranded whales were emaciated, the UME cause remains "unknown" (National Oceanic and Atmospheric Association, 2021). Hormone analysis of these animals would be beneficial as it could provide valuable information on stress response leading up to, during and, eventually, following the UME.

\section{CONCLUSION}

This is the first report of a large steroid hormone panel, using only $50 \mathrm{mg} \mathrm{ww}$ of tissue, in any cetacean. Our LCMS/MS methodology allows for the accurate, reliable, and concurrent analysis of a panel of up to 10 reproductive and stress hormones using single and small blubber biopsies. This provides important avenues of research for cetacean health and population demographic assessment and is thus pertinent to their conservation and management.

\section{DATA AVAILABILITY STATEMENT}

The raw data supporting the conclusions of this article will be made available by the authors, without undue reservation.

\section{ETHICS STATEMENT}

The animal study was reviewed and approved by the Ethics Committee of the Subsecretaría de Gestión Para La 
Protectión Ambiental of the Mexican Dirección General de Vida Silvestre.

\section{AUTHOR CONTRIBUTIONS}

CW: methodology, validation, formal analysis, investigation, data curation, writing-original draft, writing-review and editing, and visualization. JU: conceptualization, resources, writing-review and editing, project administration, funding acquisition. DB-S: formal analysis, resources, writing-review and editing. SM-A: resources, writing-review and editing. SS: resources, investigation, data curation, and writing-review and editing. JS: formal analysis, data curation, writingreview and editing. $\mathrm{ML}$ and $\mathrm{NK}$ : methodology, writingreview and editing. $\mathrm{BH}$ and $\mathrm{PD}$ : resources, writing-review and editing. $\mathrm{MK}$ and $\mathrm{KB}$ : investigation, writing-review and editing. CG-C: conceptualization, methodology, validation, resources, writing_original draft, writing-review and editing,

\section{REFERENCES}

Atkinson, S., Combelles, C., Vincent, D., Nachtigall, P., Pawloski, J., and Breese, M. (1999). Monitoring of progesterone in captive female false killer whales, Pseudorca crassidens. Gen. Comp. Endocrinol. 115, 323-332. doi: 10.1006/gcen. 1999.7319

Atkinson, S., Crocker, D., Houser, D., and Mashburn, K. (2015). Stress physiology in marine mammals: how well do they fit the terrestrial model? J. Comp. Physiol. B 185, 463-486. doi: 10.1007/s00360-015-0901-0

Atkinson, S., Gendron, D., Branch, T., Mashburn, K., Melica, V., Enriques-Paredes, L., et al. (2020). Pregnancy rate and biomarker validations from the blubber of eastern North Pacific blue whales. Mar. Mamm. Sci. 36, 6-28. doi: 10.1111/mms. 12616

Barratclough, A., Wells, R. S., Schwacke, L. H., Rowles, T. K., Gomez, F. M., Fauquier, D. A., et al. (2019). Health assessments of common bottlenose dolphins (Tursiops truncatus): past, present, and potential conservation applications. Front. Vet. Sci. 6:444. doi: 10.3389/fvets.2019.00444

Bechshoft, T., Wright, A. J., Styrishave, B., and Houser, D. (2020). Measuring and validating concentrations of steroid hormones in the skin of bottlenose dolphins (Tursiops truncatus). Conserv. Physiol. 8:coaa03. doi: 10.1093/conphys/ coaa032

Boggs, A. S., Ragland, J. M., Zolman, E. S., Schock, T. B., Morey, J. S., Galligan, T. M., et al. (2019). Remote blubber sampling paired with liquid chromatography tandem mass spectrometry for steroidal endocrinology in freeranging bottlenose dolphins (Tursiops truncatus). Gen. Comp. Endocrinol. 281, 164-172. doi: 10.1016/j.ygcen.2019.06.006

Boggs, A. S., Schock, T. B., Schwacke, L. H., Galligan, T. M., Morey, J. S., McFee, W. E., et al. (2017). Rapid and reliable steroid hormone profiling in Tursiops truncatus blubber using liquid chromatography tandem mass spectrometry (LC-MS/MS). Anal. Bioanal. Chem. 409, 5019-5029. doi: 10.1007/s00216-0170446-z

Boots, L. R., Potter, S., Potter, H. D., and Azziz, R. (1998). Measurement of total serum testosterone levels using commercially available kits: high degree of between-kit variability. Fertil. Steril. 69, 286-292. doi: 10.1016/S0015-0282(97) 00464-0

Carone, E., Pardo, M. A., Atkinson, S., Mashburn, K., Pérez-Puig, H., EnríquezParedes, L., et al. (2019). Sex steroid hormones and behavior reveal seasonal reproduction in a resident fin whale population. Conserv. Physiol. 7:coz059. doi: 10.1093/conphys/coz059

Cates, K. A., Atkinson, S., Gabriele, C. M., Pack, A. A., Straley, J. M., Yin, S., et al. (2019). Testosterone trends within and across seasons in male humpback whales (Megaptera novaeangliae) from Hawaii and Alaska. Gen. Comp. Endocrinol. 279, 164-173. doi: 10.1016/j.ygcen.2019.03.013 visualization, supervision, project administration, funding acquisition. All authors contributed to the article and approved the submitted version.

\section{FUNDING}

This work was supported by the Texas Tech University.

\section{ACKNOWLEDGMENTS}

This work was conducted under NMFS Office of Protected Resources' Marine Mammal Health and Stranding Response Program (MMHSRP) permit 18786 and 18786-02. We thank Teri Rowles (National Marine Fisheries Service, Silver spring, MD), Erangi Heenken (Purdue University), and Mike Scott for assistance with the project. We thank all collaborators involved in the collection and processing of samples.

Cates, K. A., Atkinson, S., Pack, A. A., Straley, J. M., Gabriele, C. M., and Yin, S. (2020). Corticosterone in Central North Pacific male humpback whales (Megaptera novaeangliae): pairing sighting histories with endocrine markers to assess stress. Gen. Comp. Endocrinol. 296:113540. doi: 10.1016/j.ygcen.2020. 113540

Chace, D. H. (2001). Mass spectrometry in the clinical laboratory. Chem. Rev. 101, $445-478$.

Champagne, C. D., Kellar, N. M., Crocker, D. E., Wasser, S. K., Booth, R. K., Trego, M. L., et al. (2017). Blubber cortisol qualitatively reflects circulating cortisol concentrations in bottlenose dolphins. Mar. Mamm. Sci. 33, 134-153. doi: $10.1111 / \mathrm{mms} .12352$

Christiansen, F., Rodríguez-González, F., Martínez-Aguilar, S., Urbán, J., Swartz, S., Warick, H., et al. (2021). Poor body condition associated with an unusual mortality event in gray whales. Mar. Ecol. Prog. Ser. 658, 237-252. doi: 10.3354/ meps 13585

Dalle Luche, G., Bengtson Nash, S., Kucklick, J. R., Mingramm, F. M., and Boggs, A. S. (2019). Liquid chromatography tandem mass spectrometry for the quantification of steroid hormone profiles in blubber from stranded humpback whales (Megaptera novaeangliae). Conserv. Physiol. 7:coz030. doi: 10.1093/ conphys/coz030

Dalle Luche, G., Boggs, A. S., Kucklick, J. R., Groß, J., Hawker, D. W., and Nash, S. B. (2020). Androstenedione and testosterone but not progesterone are potential biomarkers of pregnancy in Humpback Whales (Megaptera novaeangliae) approaching parturition. Sci. Rep. 10:2954. doi: 10.1038/s41598020-58933-4

Dalle Luche, G., Boggs, A. S., Kucklick, J. R., Hawker, D. W., Wisse, J. H., and Nash, S. B. (2021). Steroid hormone profiles and body conditions of migrating male humpback whales (Megaptera novaeangliae). Gen. Comp. Endocrinol. 313:113888. doi: 10.1016/j.ygcen.2021.113888

Fair, P. A., and Becker, P. R. (2000). Review of stress in marine mammals. J. Aquat. Ecosyst. Stress Recov. 7, 335-354. doi: 10.1023/A:1009968113079

Fair, P. A., Schaefer, A. M., Romano, T. A., Bossart, G. D., Lamb, S. V., and Reif, J. S. (2014). Stress response of wild bottlenose dolphins (Tursiops truncatus) during capture-release health assessment studies. Gen. Comp. Endocrinol. 206, 203-212. doi: 10.1016/j.ygcen.2014.07.002

Fanelli, F., Belluomo, I., Di Lallo, V. D., Cuomo, G., De Iasio, R., Baccini, M., et al. (2011). Serum steroid profiling by isotopic dilution-liquid chromatographymass spectrometry: comparison with current immunoassays and reference intervals in healthy adults. Steroids 76, 244-253. doi: 10.1016/j.steroids.2010. 11.005

Galligan, T. M., Balmer, B. C., Schwacke, L. H., Bolton, J. L., Quigley, B. M., Rosel, P. E., et al. (2019). Examining the relationships between blubber steroid hormones and persistent organic pollutants in common 
bottlenose dolphins. Environ. Pollut. 249, 982-991. doi: 10.1016/j.envpol.2019. 03.083

Galligan, T. M., Boggs, A. S., Balmer, B. C., Rowles, T., Smith, C. R., Townsend, F., et al. (2020). Blubber steroid hormone profiles as indicators of physiological state in free-ranging common bottlenose dolphins (Tursiops truncatus). Comp. Biochem. Physiol. A Mol. Integr. Physiol. 239:110583. doi: 10.1016/j.cbpa.2019. 110583

Galligan, T. M., Schwacke, L. H., McFee, W. E., and Boggs, A. S. (2018). Evidence for cortisol-cortisone metabolism by marine mammal blubber. Mar. Biol. 165:114. doi: 10.1007/s00227-018-3373-4

Godard, C. A., Smolowitz, R. M., Wilson, J. Y., Payne, R. S., and Stegeman, J. J. (2004). Induction of cetacean cytochrome P4501A1 by $\beta$-naphthoflavone exposure of skin biopsy slices. Toxicol. Sci. 80, 268-275. doi: 10.1093/toxsci/ kfh 124

Godard-Codding, C. A. J., Clark, R., Fossi, M. C., Marsili, L., Maltese, S., West, A. G., et al. (2011). Pacific Ocean-wide profile of CYP1A1 expression, stable carbon and nitrogen isotope ratios, and organic contaminant burden in sperm whale skin biopsies. Environ. Health Perspect. 119, 337-343. doi: 10.1289/ehp. 0901809

Goertz, C. E., Burek-Huntington, K., Royer, K., Quakenbush, L., Clauss, T., Hobbs, R., et al. (2019). Comparing progesterone in blubber and serum to assess pregnancy in wild beluga whales (Delphinapterus leucas). Conserv. Physiol. 7:coz071. doi: 10.1093/conphys/coz071

Graham, K. M., Burgess, E. A., and Rolland, R. M. (2021). Stress and reproductive events detected in North Atlantic right whale blubber using a simplified hormone extraction protocol. Conserv. Physiol. 9:coaa133. doi: 10.1093/ conphys/coaal33

Hayden, M., Bhawal, R., Escobedo, J., Harmon, C., O’Hara', T., Klein, D., et al. (2017). Nano-LC-MS/MS analysis of steroids from gray whale blubber. Rapid Commun. Mass Spectrometry. 31, 1088-1094. doi: 10.1002/rcm. 7884

Hunt, K. E., Lysiak, N. S., Robbins, J., Moore, M. J., Seton, R. E., Torres, L., (2017). Multiple steroid and thyroid hormones detected in baleen from eight whale species. Conserv. Physiol. 5. doi: 10.1093/conphys/cox061

Hunt, K. E., Stimmelmayr, R., George, C., Hanns, C., Suydam, R., Brower, H., et al. (2014). Baleen hormones: a novel tool for retrospective assessment of stress and reproduction in bowhead whales (Balaena mysticetus). Conserv. Physiol. 2, 1-12. doi: 10.1093/conphys/cou030

Iga, K., Fukui, Y., Miyamoto, A., Ishikawa, H., and Ohsumi, S. (1996). Endocrinological observations of female minke whales (Balaenoptera acutorostrata). Mar. Mamm. Sci. 12, 296-301. doi: 10.1111/j.1748-7692. 1996.tb00580.x

Keay, J. M., Singh, J., Gaunt, M. C., and Kaur, T. (2006). Fecal glucocorticoids and their metabolites as indicators of stress in various mammalian species: a literature review. J. Zoo Wildl. Med. 37, 234-244. doi: 10.1638/05050.1

Kellar, N. M., Catelani, K. N., Robbins, M. N., Trego, M. L., Allen, C. D., Danil, K., et al. (2015). Blubber cortisol: a potential tool for assessing stress response in free-ranging dolphins without effects due to sampling. PLoS One 10:e115257. doi: 10.1371 /journal.pone.0115257

Kellar, N. M., Keliher, J., Trego, M. L., Catelani, K. N., Hanns, C., George, J. C., et al. (2013). Variation of bowhead whale progesterone concentrations across demographic groups and sample matrices. Endanger. Species Res. 22, 61-72. doi: 10.3354/esr00537

Kellar, N. M., Trego, M. L., Marks, C. I., and Dizon, A. E. (2006). Determining pregnancy from blubber in three species of delphinids. Mar. Mamm. Sci. 22, 1-6. doi: 10.1111/j.1748-7692.2006.00001.x

Kellar, N. M., Trego, M. L., Marks, C. I., Chivers, S. J., Danil, K., and Archer, F. I. (2009). Blubber testosterone: a potential marker of male reproductive status in short-beaked common dolphins. Mar. Mamm. Sci. 25, 507-522. doi: 10.1111/j.1748-7692.2009.00291.x

Kershaw, J. L., and Hall, A. J. (2016). Seasonal variation in harbour seal (Phoca vitulina) blubber cortisol. A novel indicator of physiological state? Sci. Rep. 6:21889. doi: 10.1038/srep21889

Kershaw, J. L., Sherrill, M., Davison, N., Brownlow, A., and Hall, A. J. (2017). Evaluating morphometric and metabolic markers of body condition in a small cetacean, the harbor porpoise (Phoceona phoceona). Ecol. Evol. 7, 3494-3506. doi: $10.1002 /$ ece 3.2891
Koopman, H. N. (2007). Phylogenetic, ecological, and ontogenetic factors influencing the biochemical structure of the blubber of odontocetes. Mar. Biol. 151, 277-291. doi: 10.1007/s00227-006-0489-8

Krahn, M. M., Ylitalo, G. M., Burrows, D. G., Calambokidis, J., Moore, S. E., Gosho, M., et al. (2001). Organochlorine contaminant concentrations and lipid profiles in eastern North Pacific gray whales (Eschrichtius robustus). J. Cetacean Res. Manage. 3, 19-29. doi: 10.47536/jcrm.vli1

Kushnir, M. M., Rockwood, A. L., Roberts, W. L., Yue, B., Bergquist, J., and Meikle, A. W. (2011). Liquid chromatography tandem mass spectrometry for analysis of steroids in clinical laboratories. Clin. Biochem. 44, 77-88. doi: 10.1016/j. clinbiochem.2010.07.008

Lemos, L. S., Olsen, A., Smith, A., Chandler, T. E., Larson, S., Hunt, K., et al. (2020b). Assessment of fecal steroid and thyroid hormone metabolites in eastern North Pacific gray whales. Conserv. Physiol. 8:coaa110. doi: 10.1093/ conphys/coaal10

Lemos, L. S., Burnett, J. D., Chandler, T. E., Sumich, J. L., and Torres, L. G. (2020a). Intra-and inter-annual variation in gray whale body condition on a foraging ground. Ecosphere 11:e03094.

Mansour, A. A., Mkay, D. W., Lien, J., Orr, J. C., Banoub, J. H., Øien, N., et al. (2002). Determination of pregnancy status from blubber samples in minke whales (Balaenoptera acutorostrata). Mar. Mamm. Sci. 18, 112-120. doi: 10. 1111/j.1748-7692.2002.tb01022.x

McCormick, S. D., and Romero, L. M. (2017). Conservation endocrinology. BioScience 67, 429-442. doi: 10.1093/biosci/bix026

Melica, V., Atkinson, S., Calambokidis, J., Lang, A., Scordino, J., and Mueter, F. (2021). Application of endocrine biomarkers to update information on reproductive physiology in gray whale (Eschrichtius robustus). PLoS One 16:e0255368. doi: 10.1371/journal.pone.0255368

Mello, D. M., and Oliveira, C. A. (2016). Biological matrices for sampling freeranging cetaceans and the implications of their use for reproductive endocrine monitoring. Mamm. Rev. 46, 77-91. doi: 10.1111/mam.12055

Mingramm, F. M. J., Keeley, T., Whitworth, D. J., and Dunlop, R. A. (2020). Blubber cortisol levels in humpback whales (Megaptera novaeangliae): a measure of physiological stress without effects from sampling. Gen. Comp. Endocrinol. 291:113436. doi: 10.1016/j.ygcen.2020.113436

Mingramm, F. M., Keeley, T., Whitworth, D. J., and Dunlop, R. A. (2019). Relationships between blubber and respiratory vapour steroid hormone concentrations in humpback whales (Megaptera novaeangliae). Aquat. Mamm. 45, 465-477. doi: 10.1578/AM.45.5.2019.465

National Oceanic and Atmospheric Association (2021). Active and Closed Unusual Mortality Events. Available online at: https://www.fisheries.noaa.gov/national/ marine-life-distress/active-and-closed-unusual-mortality-events (accessed October 29, 2021).

Parsons, E. C., Baulch, S., Bechshoft, T., Bellazzi, G., Bouchet, P., Cosentino, A. M., et al. (2015). Key research questions of global importance for cetacean conservation. Endanger. Species Res. 27, 113-118. doi: 10.3354/esr00655

Pellegrini, T. R., Hasan, M. T., and Ma, R. (2017). Modeling of paired zeroinflated continuous data without breaking down paired designs. J. Appl. Stat. 44, 2427-2443. doi: 10.1080/02664763.2016.1254734

Rotmensch, S., and Cole, L. A. (2000). False diagnosis and needless therapy of presumed malignant disease in women with false-positive human chorionic gonadotropin concentrations. Lancet 355, 712-715. doi: 10.1016/S01406736(00)01324-6

Ruchonnet, D., Boutoute, M., Guinet, C., and Mayzaud, P. (2006). Fatty acid composition of Mediterranean fin whale Balaenoptera physalus blubber with respect to body heterogeneity and trophic interaction. Mar. Ecol. Prog. Ser. 311, 165-174. doi: 10.3354/meps311165

Schwacke, L. H., Smith, C. R., Townsend, F. I., Wells, R. S., Hart, L. B., Balmer, B. C., et al. (2014). Health of common bottlenose dolphins (Tursiops truncatus) in Barataria Bay, Louisiana, following the Deepwater horizon oil spill. Environ. Sci. Technol. 48, 93-103. doi: 10.1021/es403610f

Shackleton, C. (2010). Clinical steroid mass spectrometry: a 45-year history culminating in HPLC-MS/MS becoming an essential tool for patient diagnosis. J. Steroid Biochem. Mol. Biol. 121, 481-490. doi: 10.1016/j.jsbmb.2010.02.017

Soldin, O. P., Guo, T., Weiderpass, E., Tractenberg, R. E., Hilakivi-Clarke, L., and Soldin, S. J. (2005). Steroid hormone levels in pregnancy and 1 year postpartum using isotope dilution tandem mass spectrometry. Fertil. Steril. 84, 701-710. doi: 10.1016/j.fertnstert.2005.02.045 
Teerlink, S., Horstmann, L., and Witteveen, B. (2018). Humpback whale (Megaptera novaeangliae) blubber steroid hormone concentration to evaluate chronic stress response from whale-watching vessels. Aquat. Mamm. 44, 411425. doi: 10.1578/AM.44.4.2018.411

Thompson, L. A., Spoon, T. R., Goertz, C. E., Hobbs, R. C., and Romano, T. A. (2014). Blow collection as a non-invasive method for measuring cortisol in the beluga (Delphinapterus leucas). PLoS One 9:e114062. doi: 10.1371/journal.pone. 0114062

Trana, M. R., Roth, J. D., Tomy, G. T., Anderson, W. G., and Ferguson, S. H. (2016). Increased blubber cortisol in ice-entrapped beluga whales (Delphinapterus leucas). Polar Biol. 39, 1563-1569. doi: 10.1007/s00300-0151881-y

Trego, M. L., Kellar, N. M., and Danil, K. (2013). Validation of blubber progesterone concentrations for pregnancy determination in three dolphin species and a porpoise. PLoS One 8:e69709. doi: 10.1371/journal.pone.006 9709

Trumble, S. J., Norman, S. A., Crain, D. D., Mansouri, F., Winfield, Z. C., Sabin, R., et al. (2018). Baleen whale cortisol levels reveal a physiological response to 20th century whaling. Nat. Commun. 9:4587. doi: 10.1038/s41467-01807044-w

Walker, L. A., Cornell, L., Dahl, K. D., Czekala, N. M., Dargen, C. M., Joseph, B., et al. (1988). Urinary concentrations of ovarian steroid hormone metabolites and bioactive follicle-stimulating hormone in killer whales (Orcinus orchus) during ovarian cycles and pregnancy. Biol. Reprod. 39, 1013-1020. doi: 10.1095/ biolreprod39.5.1013

West, K. L., Atkinson, S., Carmichael, M. J., Sweeney, J. C., Krames, B., and Krames, J. (2000). Concentrations of progesterone in milk from bottlenose dolphins during different reproductive states. Gen. Comp. Endocrinol. 117, 218-224. doi: $10.1006 /$ gcen.2000.7404
Whitehead, S. J., French, J., Brookes, M. J., Ford, C., and Gama, R. (2013). Betweenassay variability of faecal calprotectin enzyme-linked immunosorbent assay kits. Ann. Clin. Biochem. 50, 53-61. doi: 10.1258/acb.2012.011272

Wittmaack, C., Lahvis, G. P., Keith, E. O., and Self-Sullivan, C. (2015). Diagnosing domoic acid toxicosis in the California sea lion (Zalophus californianus) using behavioral criteria: a novel approach. Zoo Biol. 34, 314-320. doi: 10.1002/zoo. 21217

Yoshioka, M., Okumura, T., Aida, K., and Fujise, Y. (1994). A proposed technique for quantifying muscle progesterone content in minke whales (Balaenoptera acutorostrata). Can. J. Zool. 72, 368-370. doi: 10.1139/z94-051

Conflict of Interest: The authors declare that the research was conducted in the absence of any commercial or financial relationships that could be construed as a potential conflict of interest.

Publisher's Note: All claims expressed in this article are solely those of the authors and do not necessarily represent those of their affiliated organizations, or those of the publisher, the editors and the reviewers. Any product that may be evaluated in this article, or claim that may be made by its manufacturer, is not guaranteed or endorsed by the publisher.

Copyright (C) 2022 Wittmaack, Urbán Ramírez, Bernot-Simon, Martínez-Aguilar, Subbiah, Surles, Looney, Kumar, Halaska, Duignan, Knauss, Burns and GodardCodding. This is an open-access article distributed under the terms of the Creative Commons Attribution License (CC BY). The use, distribution or reproduction in other forums is permitted, provided the original author(s) and the copyright owner(s) are credited and that the original publication in this journal is cited, in accordance with accepted academic practice. No use, distribution or reproduction is permitted which does not comply with these terms. 